\title{
CORPOREIZAR LA SONORIDAD A TRAVÉS DE LA DANZA: LOS ECOS RÍTMICOS DE STRAVINSKY EN EL BALLET iTMOi DE AKRAM KHAN
}

\section{Cintia Borges Carreras}

Investigadora independiente

\section{Resumen}

El despertar sonoro del cuerpo, en su rítmica existencia, remite a una esencia ritual como la aspiración más pura de lo que la danza irradia en la humanidad. Música, danza y poesía ¿no fueron en un tiempo mousiké? ¿no fueron las mismas, junto con la plástica, las que aparecen mimetizadas en una idealización del modelo escénico teatral? Entonces, ¿por qué limitar las confluencias interartísticas en la expresión del pathos discursivo del ser humano? Los ecos sonoros de Stravinsky, son el pretexto que justifica hacer del sonido que se halla en la danza, los ecos rítmicos de un narrar no exclusivo de una sola gramática. Los textos se suceden alrededor de un aura mítico-ritual en la que la abstracción de los espacios latentes rescata la voz de un otro, que puede ser un yo o un nosotros. La espiritualidad rítmica se emite como discurso semántico por el que hacer del cuerpo sonido, de la voz escucha, del ruido melodía y de la armonía cuerpo. iTMOi de Khan, será así la evolución de esta lectura plural del cuerpo sonoro.

Palabras clave: CUERPO; SONIDO; DANZA; RITMO; STRAVINSKI, ÍGOR (18821971)

\section{EMBODYING SOUND THROUGH DANCE: STRAVINSKY'S RHYTHMIC ECHOES IN AKRAM KHAN'S ITMOi BALLET}

\section{Abstract}

The sound awakening of the body, in its rhythmic existence, refers to a ritual essence as the purest aspiration of what dance beam in humanity. Music, dance and poetry, were they not once mousiké? Were they not the same, together with the visual arts, those that appear mimicmized in an idealization of the theatrical stage model? So, why limit interartistic confluences in the expression of human discursive pathos? Stravinsky's sonorous echoes are the pretext that justifies making the sound found in dance, the rhythmic echoes of a narration that is not exclusive to a single grammar. The texts take place around a mythical-ritual aura in which the abstraction of latent spaces rescues the voice of an-other, which can be a self or an us. Rhythmic spirituality is issued as a semantic discourse by which to make the body sound, the voice listed, the noise melody and the harmony body. Khan's ITMOi, will be the evolution of this plural reading of the sound body.

Keywords: BODY; SOUND; DANCE; RHYTHM; STRAVINSKI, IGOR (1882-1971)

\footnotetext{
Borges Carreras, Cintia. 2021. "Corporeizar la sonoridad a través de la danza: Los ecos rítmicos de Stravinsky en el ballet iTMOi de Akram Khan". AusArt 9 (1): 223-234. DOI: 10.1387/ausart.22661
}

\section{AUSART}




\section{Y ENTONCES, EN UN PRINCIPIO, LOS ECOS CORPÓREO-SONOROS DEL ARTE}

En un principio, en aquel tiempo remoto que la antropología, la religión y la historia han tratado de delimitar, de narrar y de explicar, el arte era todo uno. Las voces emitían sonidos guturales que recogían la emoción más pura y visceral hasta el momento escuchada; los tambores resonaban acompañados del golpear de cañas, del aullido de cuernos o del pisar de los cuerpos alrededor de la lumbre; y en sus experiencias extracorpóreas, el mundo iba configurándose desde una sacralidad ritual. El arrullo de la aurora se fue sucediendo, en el vivir cíclico de la naturaleza, y entones los griegos, al son del kithara entonaron la melodía mítica de Ulises, dotaron de razón a la virtud musical, no irreductible esta a una única destreza, si no extensiva, en cambio, al resto de las Musas. Las divinidades se hicieron afines a la mousiké, dando nombre a todo aquello que era regalado por un don celestial, sin intervención del ser humano, aunque fuesen sus dedos los que moldeasen la figura de Galatea o los mismos que punteaban las cuerdas de la lira de Orfeo.

¿Hubimos de esperar a idealizar una posible 'obra de arte del futuro' para recuperar su retórica, en el efectismo que opera en la acción dialógica de las artes? Más todavía, lo viejo se vanagloria de ser el motor que rige los presupuestos de nuevos cánones hacia el anhelo de pureza artística, presentando lo que es ancestral en la cima de una modernidad. La tendencia interartística apareció como un icono de la vanguardia, los paradigmas jerárquicos delimitaron paisajes de sumisión impuesta a cierto canon o preceptiva, cediéndose a comparaciones no siempre equilibradas. Su red se forja a partir de la alianza de la imagen representada en el complejo emocional constituido desde la analogía metafórica, desde la reunión acompasada e intencional intertextual o desde la accidental evocación de su fenómeno estético. De este modo, sus signos pueden aún en la ausencia del otro, sucumbir a la reproducción metamórfica de su propio contar expresivo. Ausencia, no por darse a algún tipo de incapacidad resolutiva pues los recursos, aunque intercambiables, no son sustituibles.

La ausencia ha formado parte de la naturaleza de la imagen visual desde sus orígenes y su fuerza ha residido, [...] en el poder de restaurar esa ausencia. Por otra parte, es sabido que literatura no surgió en solitario, sino acompañada de la música y la danza, 
es decir, junto con la manifestación más abstracta y la expresión donde la presencia del cuerpo instala una máxima materialidad.

(Gabrieloni 2009, 125)

La poiesis implícita en el entramado compositivo de las artes tiende a fragmentarse, pero ¿no es también cierto, que tanto la mousiké griega como la Gesamtkunstwerk wagneriana ${ }^{1}$, se identifican en obras que tienen en su ser los textos de un compendio de gramáticas, que no siempre reclaman ese estatus? Isadora Duncan era afín a estos principios, pero le otorgó un rango de subordinación a la danza desde un modelo musical como el que se encuentra en Parsifal (1882), gracias al que: "la danza, tan largamente sin vida en el embrión, ha nacido de nuevo" (Duncan [1928] 2008, 134). La llamada Obra de Arte Total "se deja caracterizar en el ámbito estético mediante una frenética búsqueda de grandeza, reconocimiento y ascenso social que en ocasiones lo conduce a un verdadero delirio gigantomáquico" (Portales 2012, 123). En este delirio, ya atribuido al ditirambo dionisíaco, la máscara, como así recuerda Marifé Santiago $(2020,147)$, otorga la posibilidad de autodefinirse como arquetipo que transgrede los rasgos propios que transforman lo existente. "Suerte de protectora del fuego de la luz primordial que se repite con el poder del abrazo de la serpiente originaria cada vez que asistimos al Teatro como una ceremonia donde lo sagrado aparece" (ibíd., 155). Y en su simbolismo, los sentidos de la música coreografiada se muestran a la espera de su perceptibilidad. ¿Quizás en la reinstauración de las ideas nietzscheanas desarrolladas en El nacimiento de la tragedia hacia la proposición de un lenguaje fisiológico que afecte tanto al hacedor artístico como al receptor? Quizás, en su dualidad, los instintos se despiertan, a expensas de ese supuesto desorden de los sentidos convocados en el rendimiento del arte musical, como dispensador de una reflexión socializada en el lenguaje de imágenes corpóreas. También, porque son parte del mecanismo de la experiencia estética:

Ella brota del cuerpo y sus instintos, de la sensibilidad [...] Cuerpo y espíritu, animalidad instintiva espontánea y capacidad racional reflexiva resultan de esta manera integradas en la acción de la embriaguez de la que brota el arte y que se intensifica ante el mismo.

(Gama 2008, 100)

Nietzsche ([1872] 2004, 46) decía que bajo los efectos de lo dionisíaco los seres humanos revitalizan la alianza que les hace entidades afines a la naturaleza, lo musical puede hacerse pictórico, en el mismo equilibrio en el que lo danzado se hace armonía y sus sonidos emiten danza. "El barro más noble, 
el mármol más precioso son aquí amasados y tallados, el ser humano, y a los golpes de cincel del artista dionisíaco de los mundos resuena la llamada de los misterios eleusinos" (ibíd., 46-7). En la apariencia destructora de Dionisos, de desbordante irrigación restaurada, la razón apolínea, se introduce como equilibrio. Las formas se quiebran, pero con un límite impuesto por la apariencia, como en la claridad de las líneas de Georges Balanchine, en una intuición de la naturalidad racional de un cuerpo cognoscitivo que toma la temporalidad de la música, para exhibir también, la embriaguez de los diálogos internos de la armonía de Stravinsky² (Joseph 2002).

La técnica es parte de este oficio, por eso, a partir de su dominio, se puede tornar al cuerpo de roles diversos, de moralidades ideológicas o de subjetividades. Ford $(2002,94)$ recupera ya en el sufijo de aquel término -mousilé-iké, el ser una habilidad que capacita para ejercer control sobre una actividad artística, cercana a la techné, cuando en esta confluye con otro concepto, el de mímesis, el ser imitativa. Una designación operante en la ramificación de distintas teorías poieticas legitimadas en cada periodo histórico, sin ser reducible a una copia ideal equilibrada de ideas inmutables.

La homogeneidad no rige la realidad práctica por la que las artes se muestran al mundo. La toma de conceptos que el ser humano gesta para autodefinirlas está condicionada por una subjetividad que pretende el orden, la clarificación de objetivos, la delimitación de su propia finitud. Disertar acerca de los procedimientos por los que, desde la estética, la sociología, la psicología, la semiología, la mitología, la filosofía, la neurociencia, la armonía o el análisis del movimiento, se componen los paradigmas teóricos alrededor de las artes, resulta un tema complejo para poder si quiera soñar en abarcarlo en estas líneas. El platonismo mimético será concerniente en la medida en que se dirige a ocupar los tiempos representacionales de un arte escénico, en el que la música es quien de mostrar los significados encarnados en las dinámicas corporales del bailarín. La teoría interartística sustenta los discursos de lo narrado por las artes como el tejido germinado de los capullos de las orugas, todavía no metamorfoseadas en mariposa. Al incorporarse en un objeto estético concreto, se entregan a la disolución de parámetros, al crecimiento de otra cutícula y al desecho de los residuos que invaliden dicha obra. Se gesta entonces el artificio del que Colomé (2007) habla, hacia la exposición de una alquimia sonoro-coreográfica, en la que ambas confluyen hacia la crítica social. La semiosis narratológica del lenguaje de la danza, hace de su texto, discursos comprometidos con una ideología reivindicativa según el contexto de cada artista. La atmósfera musical es parte de esa dramaturgia, al igual que 
las narrativas de otras manifestaciones artísticas, por eso, si cabe, la evidencia del fenómeno podría hacer redundante los puentes académicos.

En el presente artículo se pretende traspasar la exposición dogmática sobre cómo los lenguajes de la música y de la danza se articulan en el espacio teatral. La voz social, en tanto palabra, emoción, cuerpo o imagen, se hace dramaturgia en el movimiento de la danza. ¿Qué cuerpo sonoro se constituye cuando la estética artística hace de lo bello o de lo sublime una realidad de un mundo en ocasiones deshumanizado? ¿Qué sonido corpóreo sintetizan los artistas a través de los motivos ideológicos narrados? ¿Es en exclusiva una formulación del pathos, o se halla en su armonía rítmica estructuras que ordenan la composición y semánticas más complejas fruto de su equivalencia o contraste? La sincronía coreo-musical que el espectador percibe en la percepción de la obra escénica debería ser suficiente para romper jerarquías, hacia la valoración de la sensibilidad artística del conjunto dramatúrgico. Los términos sobre los que se ha iniciado este artículo favorecen la disposición a la escucha de dicha convergencia, destinada a generar una voz reflexiva patentizada por un autor, que incluso llega a perder el control de su obra. Observemos si no, a Stravinsky, en concreto a su sacra partitura, sobre la que no dejan de sucederse textos coreográficos sin que se llegue a agotar su significado. Incluso, si cabe, se llega a omitir la armonía atonal característica, y la declinación polirrítmica de su folclore ruso, hacia otro tipo de sonoridad en el que se retrata la atmósfera circundante al coreógrafo, pero también la ideología musical en esta otra invocación compositiva.

\section{LA NO-VOZ DE STRAVINSKY EN ITMOI DE AKRAM KHAN}

Los espacios semánticos por los que se expresa la danza abarcan, dada su mirada múltiple, texturas rítmicas que pueden estar pautadas por el diseño coreográfico, por las dinámicas del contar que presenta su narrativa o por la acción armónica marcada por la partitura. El tratamiento que se da de cada parcela no se rige siempre por la sincronía, pues de los contrastes nace también la metáfora sígnica de los conceptos operantes. Tampoco es requisito que la narración vede a la abstracción como recurso que hace mover a los bailarines, pero, entre Le sacre du printemps e iTMOi, en la diversidad de su lenguaje y su estética, hay una tendencia hacia la generación de una atmós- 
fera de marcada índole ritual. Lázzaro define la atmósfera, como "una suerte de halo o capa que envuelve la escena" $(2013,53)$, a través de la cual se percibe el imaginario expuesto de los artistas que participan en su composición. En su identificación, la subjetividad interfiere en la acción de la percepción, a partir del tejido sensorial que los medios del arte emiten desde la balaustrada de la estética.

El paradigma por el que los textos presentados en la escena, adquiere los tintes del universo social supone para Islas $(1995,24)$ la exteriorización de una ideología autorreferencial, en la medida en que es identificativa de la época. Pero, en este modelo se obvia la sonoridad interna de la obra, reflejada corporal y musicalmente; la posibilidad de la atemporalidad o de las relaciones motivadas por cuestiones estéticas. La cognición musical ha probado que el cuerpo interfiere en la escucha de la experiencia musical, como una empatía corpórea, según Meschini y Payri (2016), que toma los parámetros tanto acústicos como biomecánicos dispuestos en la escena. En este sentido se presupondría la capacidad kinética de la música para generar cambios, alterar la presencia y sumergir al espectador en un bucle hipnótico. Los sonidos armónicos incorporados a la dramaturgia de cualquier ballet se modifican en una doble dirección por estar determinados a otro ritmo, el pautado por los tempos coreográficos.

Es este tipo de somatización en las rendijas del arte, por el que el ballet iTMOi (In the mind of Igor) (2013) de Akram Khan puede aspirar a una restitución de Le sacre du printemps sin reproducir su partitura. En una composición triádica, repartida entre Nitin Sawhney, Jocelyn Pook y Ben Frost, el coreógrafo compone otro tejido sacro, en el que se preservan los delirios del ritual dionisíaco. Los gritos humanos reproducen esa animalidad del ritual en la vocalización de palabras que adquieren mayor protagonismo por la intención sonora de su inflexión modulada, que por el propio significado lingüístico. La inteligibilidad abarca también los susurros, y las campanadas marcan el compás que demarca el inicio de un tiempo ritual, remoto, primitivo. Las formulaciones repetitivas de percusión, contrastando con las melodías de los instrumentos de viento honran a la sacerdotisa, restituyendo los principios de la naturaleza humana, en su tendencia a sacrificar a un ser por el bien de la comunidad.

Este ser blanco de Khan, vestido con cierto barroquismo, se percibe análogo al chamán de Nijinsky, por la adoración que en ambos casos se transmite, a pesar de que su magia sea la de ser la novia en su boda. La música bajará su intensidad ante su entrada escénica, igual que el mover de los bailarines, 
conquistados por el estatismo o por una dinámica ralentizada, hasta que, en ambos casos, el conjunto se entrega a su honra. La pureza en su centro, en uno del ocultismo ritual, en otro de la virginidad ritual de la estructura matrimonial religiosa.

La experiencia acústica del sonido turba los cuerpos, los hace resonar en la magnificencia de las ondas, permitiendo otras sinestesias que se retratan en un tipo de percepción que trasciende la visión unilateral del arte. Los contrastes entre la dinámica corporal y la sonora generan una sensación creciente de que los designios de la naturaleza presiden los cuerpos. El movimiento de lo corporal puede verse atrapado por una convulsión extensiva, en donde el esqueleto al completo se deja afectar por la magnificencia ritual. Los textos cantados litúrgicos, de la iglesia ortodoxa rusa, reflejan una espiritualidad que no fue tan ajena para nuestro compositor. Son quien de acompañar lo sacrificial, pues ¿hay algo más puro que la voz humana?

El conocido patrón métrico de Stravinsky: un, dos, tres, cuatro, cinco, seis, siete, ocho, nueve; un, dos; un, dos... en reiteración constante, es tomado por Khan como una abstracción rítmica que corporeizar en su sonoridad. Lo cual, unido a la eclosión sacrificial de la mujer, hecha rito, supone una mitificación fantasiosa que choca con una realidad social en cuestiones de género. La mujer, describe Beatriz Martínez $(2017,121)$ entregada a la renuncia de su vivir por el del prójimo, sea este sus padres, sus hijos o su marido, es también mancillada por el arquetipo de la femme fatale en su encanto y poder. El sacrificio es el foco de un ballet que ahonda en la identidad corpórea, en lo religioso y en lo político. Su historia, es la de la humanidad; como en el mito, precisa desnudarse para trascender las estructuras establecidas. La dramaturga de iTMOi, Ruth Little, expone este interés del coreógrafo en recuperar la sonoridad ritual, a través de exhibir la contradicción humana: "the fact the human mind lies to itself, that we tell stories to another, that we create versions of ourselves that are not real, that we are in many ways always wearing masks" (Akram Khan Company 2013).

La ruptura del orden tampoco se restaura en su ballet, quizás porque esta tampoco es una premisa estable en la humanidad. Es la reescritura de lo atemporal. No hay cronologías, aunque se trate con referencias concretas de un tiempo vanguardista en la modernidad musical.

El fundamento social sugerido en el imaginario evocador de la obra se acrecienta cuando se hace tópico dramatúrgico, constituyendo una voz latente 
de la humanidad, expresada esta por la diversidad interartística que la danza favorece. La sonoridad de su estructura se amplifica por la confluencia de la pulsión energética coreográfica respecto al latir externo, imbricado a otro percutir, aquel que rige el ritmo de los tiempos musicales. $Y$ a su vez, se hace cuerpo en el tejido no visible de la estructura dramática, por la que deviene el pathos; y en su más efectiva pretensión, se llegan a tambalear los principios preestablecidos sin juicio reflexivo hacia una regeneración de la moralidad.

\section{CONCLUSIÓN: EL RITMO SONORO-COREOGRÁFICO, BAGAJE MÍTICO DEL SENTIR}

Lo que se halla tras el objeto estético, producto de la creatividad pasional y razonada del artista, configura una red emocional que compone conceptos asociados a narrares ideológicos, estéticos o psicosociales. La obra se deja ver a través de su propio discurso, por ser su lenguaje relator del decir concreto del autor, combinado con las circunstancias concretas de su realización vívida en el espacio de representación, y sujeto este siempre a una dinámica espaciotemporal determinada.

John Cage (1981), en las conversaciones con Daniel Charles, afirmaba la no dependencia de la escucha del texto artístico respecto al espacio del autor. Bien es cierto, que la estética del músico se dirigía hacia la desnudez de propósito, a través de arrebatar a lo creado cualquier intención presupuesta, que condicione al receptor. Cage $(1981,65)$, a pesar de negar la emoción porque esta contamina la apreciación perceptiva que se tiene de lo musical, está proponiendo la apertura a la que se cede cualquier obra al someterse al juicio de otras vísceras. "¡Los sonidos no tienen propósito! Viven”, clamaba (1981, 98), pero lo cierto es que en la atmósfera armónica de Jocelyn Pook, responsable de la composición de la parte musical del ballet Dust (2014) de Akram Khan, se respira el hedor de la Gran Guerra, la lucha de las mujeres para soportar la caída de las trincheras. Igual de evidente, que el tejido sacrificial de iTMOi. "La música consiste en esa vida de los sonidos, en esa participación de los sonidos en la vida, que puede convertirse [...] en una participación en la vida de los sonidos" (Cage 1981, 98). El sentido asociado a la concepción plural de la emoción dada procede de una concepción del lenguaje de las artes, habilitado para la comunicación. La dirección estructural de lo interpretado a través de 
ondas sonoras es dependiente de la gramática de la danza, en la medida en que se piensa para un espacio escénico corporal. No se trata de imponerse un lenguaje artístico sobre otro, pero ambas entidades pertenecen a un espacio de representación que está sujeto a una dinámica no privativa de una única percepción sensorial.

La obra puede componer, además de una incidencia particular según los parámetros cronológicos sobre los que se muestra en el tiempo social presente, una disposición concreta hacia un discurso humanizado que recupera la voz de los pueblos, de las individualidades marginales, de las silenciadas en la alteridad o en la otredad. La voz de los mitos es también un sonido que se construyó cercano al rito. En su oralidad, acompañaba a la tribu manifestándose percutivo en las ceremonias como relatos de un contar sapiencial en materia humana. La danza es ritmo, el cual, dado a la proporción deconstruida del movimiento cotidiano, se traza verba retórica de la ausencia, de sonoridad articulada. "Al movernos, partes diferentes de la sinfonía de las articulaciones se mueven a velocidades distintas, como polirritmias mudas. Unas partes pesan mucho y otras son muy ligeras" (Celabert 2020, 114). Sus dinámicas se componen en un espacio que supera lo tangible, tanto por hacerse texto de un narrar plural como el que puede tratar la literatura, como por incorporar las derivas armónicas de la música o modificar el tiempo espacial con la diversidad de planos coreográficos transitados en su conquista.

Su ritmo está cedido al tratamiento de ese tiempo musical, pero este no es un mero acompañamiento para transmitir algo a través de la danza, supone en cambio, una simbiosis que modifica el significado que puede tomar el movimiento. Émile J. Dalcroze dirigía la sonoridad corpórea según los acentos o dinámicas presentes en la música, hacia el acercamiento de una 'plástica animada' (Meschini \& Payri 2016, 15) arraigada en la concordancia de la energía motora, en su espacialidad y en las tensiones musicales. ¿No es esta misma plástica la que está en un ballet?

Podríamos preguntarnos por qué recurrir a John Cage, conocida su tendencia a lo aleatorio y a lo indeterminado, en un discurso que versa en torno a las lecturas ideológica de la sonoridad que se encuentra en la voz danzada de iTMOi. Es porque, a raíz de su trabajo teatral con Merce Cunningham y sus lecturas de Antonin Artaud, Cage consolida a partir de la obra Black Mountain, un tratamiento disciplinar enfocado en las "actividades artísticas, como sonidos" (Cage 1981, 204). Sonido, por estar asociado a las dinámicas que el ritmo hace mover en todos los elementos integrados en lo coreografiado. Sonido, 
por hacerse cuerpo en ese sonar social que da voz sin la emisión en sí de onda, porque resuena en el latir de la danza una plenitud del pathos humano, que puede, desde la singularidad de una época, hacerse estable en los dominios generacionales. El cuerpo de la danza suena en este espacio simbólico, pero también a través de lo técnico, en su música.

El ritmo, decía Octavio Paz (1956) "provoca una expectación, suscita un anhelar. Si se interrumpe, sentimos un choque. Algo se ha roto" (p. 106). El ritmo de las sociedades aparece retratado en la danza tanto como testimonio de vida como crítica de la existencia, sin que lo particular coarte lo universal, ese algo que está en nosotros, como espectadores, pero que también es parte de los otros imaginarios implícitos en la sonora corporeidad de lo danzado.

El ritmo de Sawhney, Pook y Frost, se entreteje en el ballet de Khan con las dinámicas coreográficas, pues el mover supone una amplificación de su sentir. ¿Y qué ocurre con el ritmo de Stravinsky? Su retrato aparece dibujado con otros aires, simbólicos en la organización dramatúrgica de la obra. La sacralidad de lo sacrificado aparece retratada en este otro ritual, en la ensoñación primaveral que los aires que el kathak imprimen en el movimiento. El folclore se aproxima más a la sonoridad oriental que a la occidental rusa. Los saltos repetidos hacia la tierra podrían evocar Le sacre de Pina Bausch, pero ¿a qué faceta atribuimos el cuerpo inmaculado, blanco en su vestir, de la mujer que interrumpe la acción? El tiempo se paraliza, su ritmo deja de estar sujeto al frenetismo, y aparece entonces la honra divina. Son otros sus sonidos.

Los sonidos de Stravinsky flashean las imágenes de tantas coreografías como reescrituras del rito conozcamos. El ritual primaveral es parte del imaginario, pero las líneas de la historia fluyen por los caminos de otra sonoridad. La de una pieza artística que podría emular el sentir de la mousiké griega, pues su poética entrelaza un tejido que fluye desde la música cíngara de Stravinsky, a través de los patrones estructurados de una sociedad, hacia la desnudez del habla humana, por los ritmos acentuados del característico estilo de Akram Khan, hasta la pluralidad discursiva de la pieza dirigida a la escena. El ritmo de aquel 1913 pervive en un trabajo colaborativo, que honra la implicación de los mitos sociales, del primitivismo ritual, a través de una sonoridad corpórea que rompe conceptos. No hay espacio para la apariencia, tampoco para negar la estética que nos precede, ni siquiera para que las ausencias despunten sobre estas poéticas. 


\section{Referencias bibliográficas}

Aizpún Vílchez, losune. 2018. "La teoría de la obra de arte total como categoría formal en el primer Romanticismo alemán". Humanidades 8(1): 1-27. http://dx.doi.org/10.15517/h. v8i1.31464

Akram Khan Company. 2013. "iTMOi- making of". Filmed at MC2: Grenoble; recorded and edited by Maxime Dos, Vídeo de Youtube, 18:08. 11 nov. https://www.youtube.com/watch?$\mathrm{v}=6 \mathrm{tpGeEks} 3 \mathrm{jE} \& \mathrm{t}=5 \mathrm{~s}$

Cage, John. 1981. Para los pájaros: Conversaciones con Daniel Charles. Traducción de Luis Justo. Caracas: Monte Ávila

Colomé y Pujol, Delfín. 2007. Pensar la danza. Madrid: Turner

Companhia Nacional de Bailado. 2013. “iTMOi vienna”. Grabado y editado por Maxime Dos en ImpulsTanz Vienna. Vídeo de Vimeo, 01:06:50. https://vimeo.com/187962344

Duncan, Isadora. (1928) 2008. El arte de la danza. Edición de José Antonio Sánchez. Madrid: Akal

Ford, Andrew. 2002. The origins of criticism: Literary culture and poetic theory in classical Greece. Princeton Oxford: Princeton University

Gabrieloni, Ana Lía. 2009. "Literatura y artes". En La investigación literaria: Problemas iniciales de una práctica, Miguel Dalmaroni dir.; Gloria Chicote et al.., 125-46. Santa Fe: Universidad Nacional de Litoral

Gama Barbosa, Luis Eduardo. 2008. "Los saberes del arte: La experiencia estética en Nietzsche". Ideas y Valores 57 (136): 69-103. https://revistas.unal.edu.co/index.php/idval/article/ view/1361

Gelabert Usle, Cesc. 2020. Lo que me gustaría que la danza fuera. Edición de Joaquim Noguero. Barcelona: Comanegra

Islas, Hilda. 1995. Tecnologías corporales: Danza, cuerpo e historia. Ciudad de México: Cenidi Danza

Joseph, Charles M. 2002. Stravinsky \& Balanchine: A journey of invention. New Haven CT: Yale University

Lázzaro, Ana Inés. 2013. "Espacio y tiempo: Materialidades simbólicas en el arte coreográfico contemporáneo". El Ornitorrinco Tachado 3: 47-55. https://ornitorrincotachado.uaemex.mx/ article/view/4632

Martínez del Fresno, Beatriz. 2017. "Mujeres en escena: Feminismo y danza contemporánea en la España de los ochenta". En Danza, género y sociedad, Beatriz Martínez del Fresno \& Ana María Diaz Olaya, coords., 113-75. Málaga: Universidad de Málaga

Meschini, Fabrizio \& Blas Payri. 2016. "Un estudio experimental sobre la influencia de la música en la coreografía: movimiento y espacio". Epistemus 4(1): 13-52. https://doi.org/10.21932/ epistemus.4.3027.1

Nietzsche, Friedrich. (1872) 2004. El nacimiento de la tragedia o Grecia y el pesimismo. Introducción, traducción y notas de Andrés Sánchez Pascual. Madrid: Alianza

Paz, Octavio. (1956) 1972. El arco y la lira; El poema; La revelación poética; Poesía e historia. Ciudad de México: Fondo de Cultura Económica 
Portales Guzmán, Gonzalo. 2012. "Nietzsche-Wagner: Preeminencia de la poesía en la obra de arte total”. Estudios Filosóficos 49: 117-25. http://dx.doi.org/10.4067/S007117132012000100007

Salas, Roger. 1985. "Elogio de la soledad”. El País, 20 nov. https://elpais.com/diario/1985/11/21/ cultura/501375609_850215.html

Santiago Bolaños, Marifé. 2020. Bailar sobre el demonio del olvido: Apuntes para una estética de la danza. Madrid: Cumbres

Schelling, Friedrich Wilhelm Joseph von. (1859) 1999. Filosofía del arte. Estudio preliminar, traducción y notas de Virginia López-Domínguez. Madrid: Tecnos

\section{Notas}

${ }^{1}$ Es a Richard Wagner a quien se le reconoce la creación de este concepto creativo, por sistematizar su teoría en La obra de arte del futuro (1849), pero, su ideal, no es para losune Aizpún (2018) atribuible en exclusiva al compositor. Esto se debe a la preeminencia de un sistema de las artes unificado a lo largo de la historia, hermanadas en planos formales, en aspectos subjetivos o por su esencia metafísica. Friedrich Schelling (1859) sugiere un acercamiento a la gesamtkunstwerk, en la integración de todas las artes en un género operístico. Escribe así en su Filosofía del arte (1802): "Música, canto, danza y todas las clases del drama viven sólo en la vida pública y se unen en ella. Donde desaparece esa vida, en lugar del drama real y exterior en que participa en todas sus formas el pueblo entero como totalidad política o ética, sólo un drama interior ideal puede reunir al pueblo" (Schelling [1859] 1999, 493). August Wilhelm Schlegel abogaba también por esa correspondencia, por la incorporación de las artes en terrenos de otras, y en K.F.E. Trahndorff, incluso aparece, en el 1827, el propio concepto.

2 La música para ballet de Igor Stravinsky lejos de estar reducida a la reconocida y polémica obra Le sacre du printemps, se diversifica en otros referentes. Los encantos fisiológicos que suponía el hacer del sonido imagen, le impulsaron a colaborar con otros coreógrafos. En referencia a la relación que tuvo con Georges Balanchine, citar el estudio monográfico de Charles M. Joseph (2002) dedicado especialmente a su producción artística: Stravinsky \& Balanchine. A Journey of invention.

\footnotetext{
(Artículo recibido: 27-03-21; aceptado: 04-06-21)
} 